\title{
Nanocellulose-Assisted Thermally Induced Growth of Silver Nanoparticles for Optical Applications
}

\author{
Calvin J. Brett,* Wiebke Ohm, Björn Fricke, Alexandros E. Alexakis, Tim Laarmann, Volker Körstgens, \\ Peter Müller-Buschbaum, L. Daniel Söderberg, * and Stephan V. Roth*
}

Cite This: ACS Appl. Mater. Interfaces 2021, 13, 27696-27704

Read Online

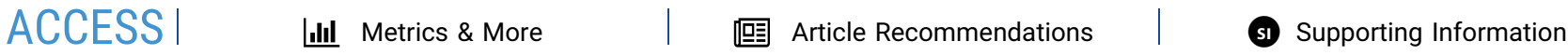

ABSTRACT: Optically responsive materials are present in everyday life, from screens to sensors. However, fabricating large-area, fossil-free materials for functional biocompatible applications is still a challenge today. Nanocelluloses from various sources, such as wood, can provide biocompatibility and are emerging candidates for templating organic optoelectronics. Silver $(\mathrm{Ag})$ in its nanoscale form shows excellent optical properties. Herein, we combine both materials using thin-film large-area spray-coating to study the fabrication of optical response applications. We characterize the Ag nanoparticle formation by X-ray scattering and UV-vis spectroscopy in situ during growth on the nanocellulose template. The morphology and optical properties of the nanocellulose film are compared to the rigid reference surface $\mathrm{SiO}_{2}$. Our results clearly show the potential to tailor the energy band gap of the resulting hybrid

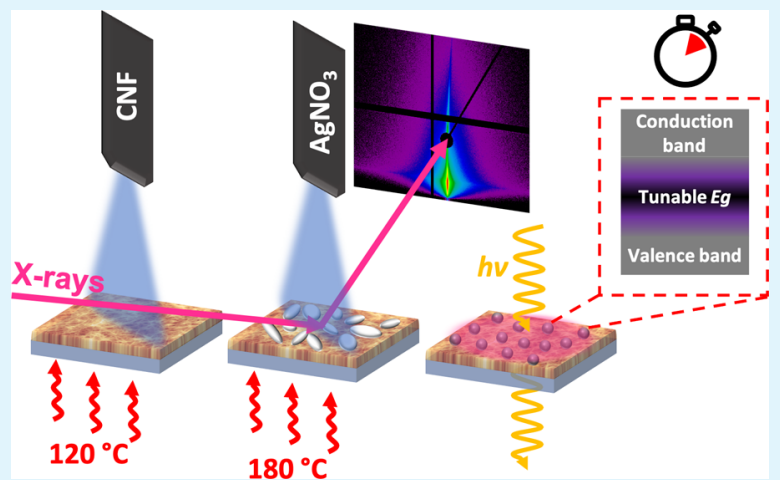
material.

KEYWORDS: cellulose, silver plasmonics, X-ray scattering, thin films, nucleation and growth, nanoparticles

\section{INTRODUCTION}

In our modern world, we are highly dependent on automation and digitalization, often through a man-machine interaction using sensors and devices that react to our input. As sustainability is one of the global challenges, we also need to increase the sustainability of these sensors and devices, ranging from the harvesting of raw materials and recyclability to endof-life processing, including environmentally friendly processes. Historically, most furniture and much of housing and construction tools have been using wood as the primary raw material. However, wood-based nanocellulose has rarely been considered as a component of smart sensors. ${ }^{1}$ The unique properties of cellulose nanofibers ( $\mathrm{CNFs}$ ) reside in their potential to provide material concepts that have high mechanical strength and stiffness at low weight together with recyclability. ${ }^{2}$ Nanocomposite material concepts, with nanocellulose as one of the main components, were shown to provide functionalities for organic supercapacitors, electrodes, and organic solar cell substrates. ${ }^{3-5}$ The effects of water on these material composites, specifically also related to stimuliresponsive changes by humidity, were studied extensively as they predominantly limit their applications. ${ }^{6-9}$ Today, functionalized nanocellulose is used in several forms ranging from films, aerogels, and dispersions to gels to enable tailored applications. ${ }^{7,10-15}$

Metallic nanoparticles of silver (Ag) or gold are excellent candidates for providing optical functionality due to their optoelectronic properties such as plasmonics. ${ }^{16}$ Plasmons provide an excellent opportunity to couple structural changes in nanostructured materials, specifically on surfaces, by their interaction with electromagnetic fields, which are strongly impacted by the structure-property relation of the surface. ${ }^{17}$ $\mathrm{Ag}$ nanowire networks are also widely used to produce transparent electric contacts using different deposition techniques such as spray-coating or $3 \mathrm{D}$-printing. ${ }^{18,19}$ Additionally, Ag nanoparticles show excellent catalytic properties and can be sprayed as films for bio-sensing applications. ${ }^{20,21}$ Thus, the combination of the unique features of nanocelluloses and optically active $\mathrm{Ag}$ nanoparticles provide an excellent opportunity for fabricating sustainable sensors for future environmentally friendly devices.

With respect to functionalization of nanocellulosic bionanocomposites using Ag nanoparticles, antimicrobial properties have been shown. ${ }^{2,23}$ For the case of bacteria-based cellulose, Ifuku et al. demonstrated the possibility to reduce $\mathrm{AgNO}_{3}$ to $\mathrm{Ag}$ nanoparticles in an aqueous state by means of the carboxyl groups on the surface of CNFs. ${ }^{24}$ Furthermore, electrically

Received: April 26, 2021

Accepted: May 26, 2021

Published: June 7, 2021 
conductive films were fabricated using $\mathrm{Ag}$ nanowires and nanocelluloses for transparent conductive papers. ${ }^{25,26}$

Thin-film fabrication can be performed using various techniques such as spin-coating, dip-coating, and spray-coating, where spray deposition is superior over most other laboratoryscale techniques in terms of scalability and the ability to control the nanostructure by tailoring the droplet sizes. ${ }^{27,28} \mathrm{By}$ tuning the deposition parameters, the surface morphology and the crystalline structure can be tailored such that the surface diffusion processes can be neglected, which is crucial for plasmonic materials. $^{29}$

The potential to understand spray-deposited cellulosic materials and to retrieve information on decomposition processes of nanoparticles in thin films has been shown by grazing incidence small-angle X-ray scattering (GISAXS). 7,30,31 By combining this with wide-angle X-ray scattering (WAXS) on wood-based materials, it is possible to correlate crystallite sizes to nanoscale structures and to extract information on the hierarchical morphology of thin films, covering a wide range of length scales. $^{32}$

In the present work, we focus on the fabrication and morphological evolution of the nanostructure during the layering of nanocellulosic plasmonic thin films as an approach to fabricate sensors. We study the impact of a porous nanocellulose substrate on the growth of $\mathrm{Ag}$ nanoparticles from an $\mathrm{Ag}$ precursor solution. A reference $\mathrm{SiO}_{2}$ surface is used to compare the influence of the substrate on the nanoparticle growth. Surface-sensitive, small-angle, and transmission WAXS techniques are applied to follow the growth of the nanoparticles on the different substrates. Scanning electron microscopy (SEM) and transmission electron microscopy (TEM) are used to sample the real space of the different sample surfaces. In transmission light spectroscopy measurements, the plasmonic behavior of the nanoparticles during the growth is studied. In summary, we elucidate that porous cellulose substrates yield a strong plasmonic absorption signal of the Ag nanoparticles using minimal material consumption. However, one aim is also to show that plasmonic effects can be achieved at minimal material consumption, contributing to lower raw material demand, lower environmental impact, as well as lower production costs.

\section{EXPERIMENTAL SECTION}

2.1. Reagents. The nanocellulose was prepared from chemically bleached wood fibers from a mixture of Norwegian spruce $(60 \%)$ and Scots pine (40\%), both from Domsjö $\mathrm{AB}$, Sweden. The fibers were treated with 2,2,6,6-tetramethylpiperidinyl-1-oxyl (TEMPO)-mediated oxidation reaction. The so-called TEMPO-CNF was prepared according to the procedure reported by Isogai et al. and was from the same batch as in previous publication by Brett et al. except that we centrifuged the dispersion at $4500 \mathrm{rpm}$ for $60 \mathrm{~min}^{7,33}$ The surface charge induced by carboxyl groups on the CNFs was $1360 \mu \mathrm{eq} / \mathrm{g}$. The dispersion used had a CNF concentration of $0.07 \mathrm{wt} \%$ in water.

For the $\mathrm{Ag}$ precursor, $50 \mathrm{mM}$ of silver nitrate $\left(\mathrm{AgNO}_{3}, \geq 99.0 \%\right.$ Sigma-Aldrich Corp.) was dissolved in ethanol (99.7\%, Carl Roth) and mixed for $15 \mathrm{~min}$ in an ultrasonic bath. The solution was used immediately without further storage.

As substrates, double-sided polished fused silica $\left(\mathrm{SiO}_{2}, \mathrm{JGS} 1\right.$, MicroChemicals $\mathrm{GmbH})$ with a thickness of $700 \mu \mathrm{m}$ and a size of $(25$ $\times 25) \mathrm{mm}^{2}$ was used. The substrates were cleaned with ethanol, acetone, and isopropanol (all Carl Roth) and subsequently flushed with ultrapure water $\left(18.2 \mathrm{M} \Omega \mathrm{cm}^{-1}\right.$, Milli-Q). Next, they were further cleaned in a highly oxidizing acid bath $(87.5 \mathrm{~mL}$ with hydrogen peroxide $30 \%, 190 \mathrm{~mL}$ sulfuric acid $96 \%, 37.5 \mathrm{~mL}$ ultrapure water, and all Carl Roth) at $80{ }^{\circ} \mathrm{C}$ for $15 \mathrm{~min}$. After the acid bath, the wafers were washed with ultrapure water and kept in it till use. Before spray deposition, the wafers were dried using a nitrogen flow.

2.2. Spray Deposition. The spray deposition on the wafers was performed at the $\mathrm{P} 03$ beamline with a beamline compatible setup. The spray device (Compact JAU D555000, Spray Systems) was remotely controlled with magnetic valves and a nitrogen flow for the spray deposition. The sample liquids were attached in a $12 \mathrm{~mL}$ glass siphon to the spray device. The spray parameters were 1 bar and 200 $\mathrm{mm}$ nozzle to sample distance. The CNF templates were prepared as in our previous publication, ${ }^{7}$ comprising spraying for $0.2 \mathrm{~s}$, waiting for $8 \mathrm{~s}$, and repeating this process 20 times at $100{ }^{\circ} \mathrm{C}$. This preparation resulted in a roughness of $2.5 \mathrm{~nm} .^{7} \mathrm{AgNO}_{3}$ was deposited by a single spray pulse for $0.2 \mathrm{~s}$ at room temperature.

2.3. X-ray Scattering. Synchrotron-based X-ray scattering experiments were performed at PETRA III, on the P03/MiNaXs beamline. GISAXS and WAXS experiments were performed to study the nanoscale and the atomic scale, respectively. All X-ray experiments were performed with an X-ray energy of $E=13.01 \mathrm{keV}$ and sample-todetector distances $\mathrm{SDD}_{\mathrm{GISAXS}}=(3471 \pm 1) \mathrm{mm}$ and $\mathrm{SDD}_{\mathrm{WAXs}}=$ $(105.9 \pm 0.5) \mathrm{mm}$. The beam size during the measurements was (15 $\times 34) \mu \mathrm{m}^{2}$. In GISAXS geometry a Pilatus $1 \mathrm{M}$ detector $\left(172 \mu \mathrm{m}^{2}\right.$ pixel size, Dectris Ltd.) and in WAXS geometry a Pilatus $300 \mathrm{k}$ detector $\left(172 \mu \mathrm{m}^{2}\right.$ pixel size, Dectris Ltd.) were used. The samples were sprayed on the beamline and subsequently measured under GISAXS conditions using an incident angle of $\alpha_{\mathrm{i}}=0.4^{\circ}$, well above all critical angles within the thin film to access full film information. ${ }^{7,34}$ The GISAXS samples were placed on a heat stage for the reflectance mode (DHS-1100, Anton Paar), allowing for annealing at the beamline. The samples were measured ex situ at room temperature and at the equilibrated temperature of $180{ }^{\circ} \mathrm{C}$ after $10 \mathrm{~min}$ of applied heat.

The WAXS samples were prepared the same way as the GISAXS samples but were measured under normal incidence in transmission geometry. During the WAXS measurements, the samples were mounted in a remotely controllable transmission heater (metal ceramic heater: HT19R; controller: TC200-EC, both Thorlabs Inc.) and the temperature was increased from room temperature to $180^{\circ} \mathrm{C}$ in the following steps: $25,100,120,130,140,150,160,170$, and 180 ${ }^{\circ} \mathrm{C}$. For both GISAXS and WAXS at each temperature step, the sample was laterally moved to distribute the X-ray dose homogeneously and to check for inhomogeneities on the sample. At each temperature step, the sample was measured at 10 spots for $200 \mathrm{~ms}$, which was then later summed up to gain higher statistics. The recorded X-ray scattering patterns were analyzed using the software packages DPDAK 1.2 and OriginPro $2018 .^{35}$

2.4. UV-Vis Spectroscopy. The samples for UV-vis spectroscopy were sprayed just before the measurements. The setup consists of the same heat stage as for the WAXS measurements. However, during the UV-vis measurements, the applied temperature was increased constantly to $180{ }^{\circ} \mathrm{C}$, with a temperature rate of $20^{\circ} \mathrm{C} / \mathrm{s}$. Every $10 \mathrm{~ms}$, a full spectrum $(200-1025 \mathrm{~nm})$ was recorded. The spectroscopic measurements were conducted using a custom-built setup. The light source is a balanced deuterium tungsten source (210-2500 nm, DH-2000-BAL, Ocean Optics), the spectrometer (200-1025 nm, OCEAN-FX-XR1-ES, Ocean Optics), the fibers (600 $\mu \mathrm{m}, \mathrm{QP} 600-1-\mathrm{SR}-\mathrm{BX}$, Ocean Optics), the collimation lens setup (185-2100 nm, UV fused silica, CVA100-COL, LA4647, both Thorlabs Inc.). The data were evaluated using the software package OceanView 1.6.5 (Ocean Optics).

2.5. Scanning Electron Microscopy. Field emission SEM measurements were conducted with a Hitachi S-4800 and a liquidnitrogen-cooled detector. The acceleration power was $5 \mathrm{kV}$ and the working distance was $3.8 \mathrm{~mm}$.

2.6. Transmission Electron Microscopy. TEM measurements were conducted with a Hitachi HT7700 on pre-sprayed copper grids. The acceleration power was $100 \mathrm{kV}$. 
a)

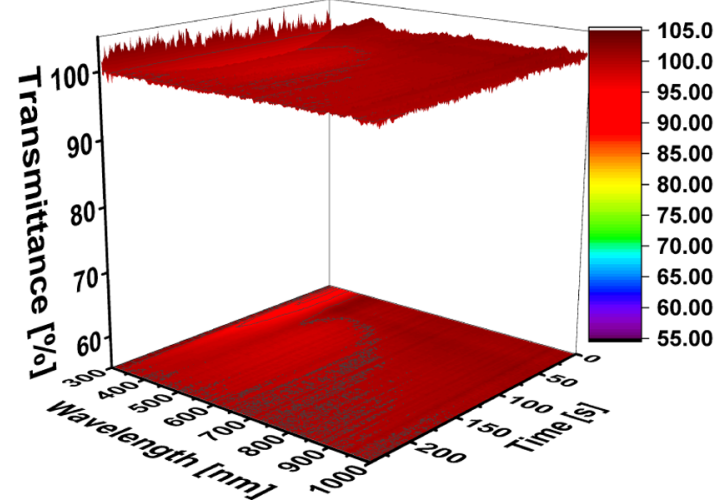

b)

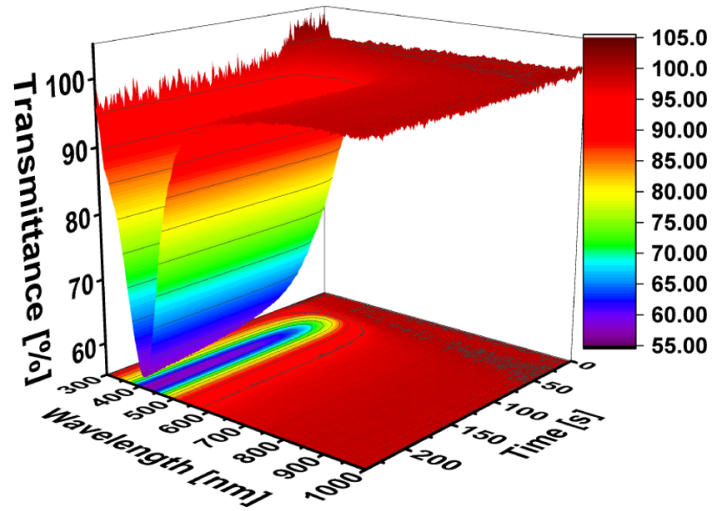

Figure 1. Transmission UV-vis spectroscopic results during the annealing and decomposition of the $\mathrm{Ag}$ precursor $(\mathrm{a})$ on silica $\left(\mathrm{SiO}_{2}\right)$ and $(\mathrm{b})$ on a CNF template. The time-dependent transmittance signal is plotted during annealing at $T=180{ }^{\circ} \mathrm{C}$.

a)

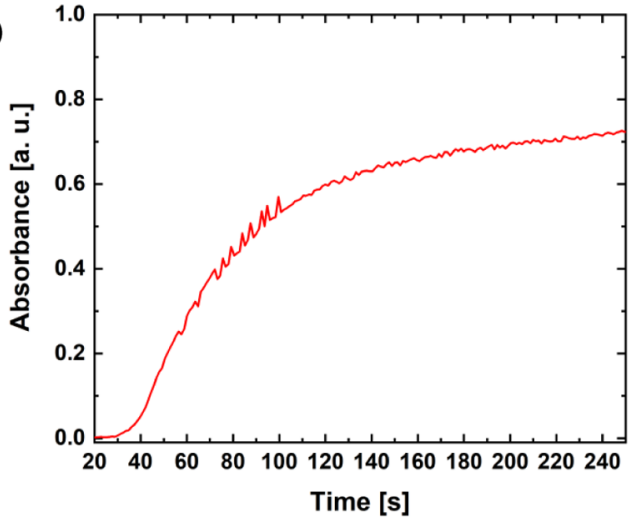

c)

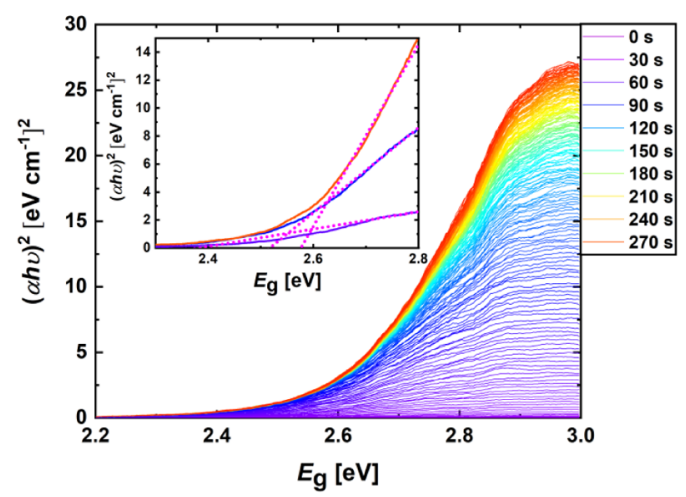

b)

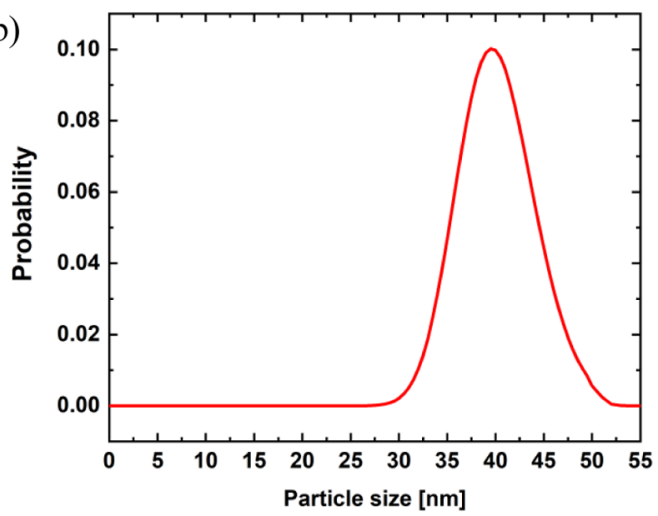

d)

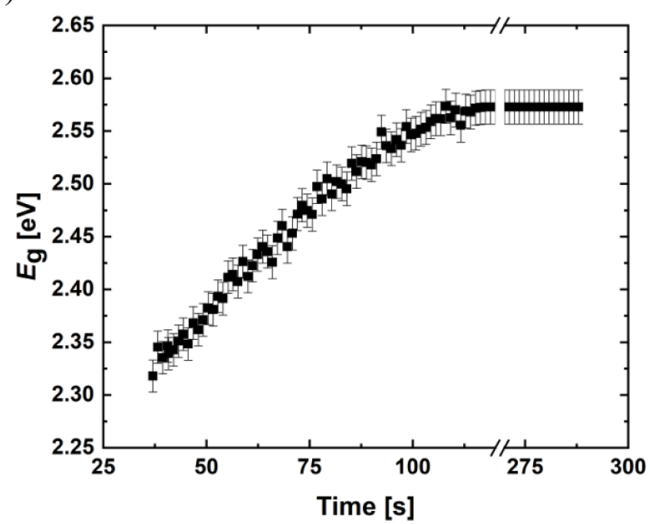

Figure 2. Optical properties extracted from spectroscopic measurements. (a) Peak absorbance of the Ag plasmonic peak. (b) Log-normal distribution of the Ag nanoparticle size on the CNF film at $T=180^{\circ} \mathrm{C}$. (c) Tauc plot. The inset in (c) shows the fitting of each curve by a linear fit in the linear region of the peak. (d) Energy band gap extracted from (c).

\section{RESULTS AND DISCUSSION}

3.1. Optical Response. Two different samples have been prepared for the UV-vis spectroscopy measurements. A single spray pulse of $\mathrm{AgNO}_{3}$ solution leading to a sub-monolayer of $\mathrm{AgNO}_{3}$ is applied on $\mathrm{SiO}_{2}$ and a CNF template (thickness 200 $\mathrm{nm}$ ). The existing inter- and intramolecular hydrogen bonds within the CNFs formed by hydroxyl groups attract the silver ions directly from the $\mathrm{AgNO}_{3}$ when deposited on the CNF template. ${ }^{36}$ The samples are dried for $5 \mathrm{~min}$, mounted in a transmission heater, where the in situ transmission UV-vis spectroscopy is performed, see Figure 1. The initial spectra are normalized to the spectrum of the corresponding substrates; hence, only changes occurring during thermal annealing are resolved. In (Figure 1a), the spectra of the $\mathrm{AgNO}_{3}$ decomposition on bare $\mathrm{SiO}_{2}$ are presented and minor effects can be observed in two regions. One region around $341 \mathrm{~nm}$, where a decline of the absorption peak can be observed, which originates from bare $\mathrm{AgNO}_{3}$, see Figure S1. In the second region, between 400 and $500 \mathrm{~nm}$, the opposite trend can be observed, a slight increase in the absorption by $3 \%$, which is an effect of the plasmonic absorption of $\mathrm{Ag}$ nanoparticles. This can also be observed for the case of Ag nanoparticle synthesis 

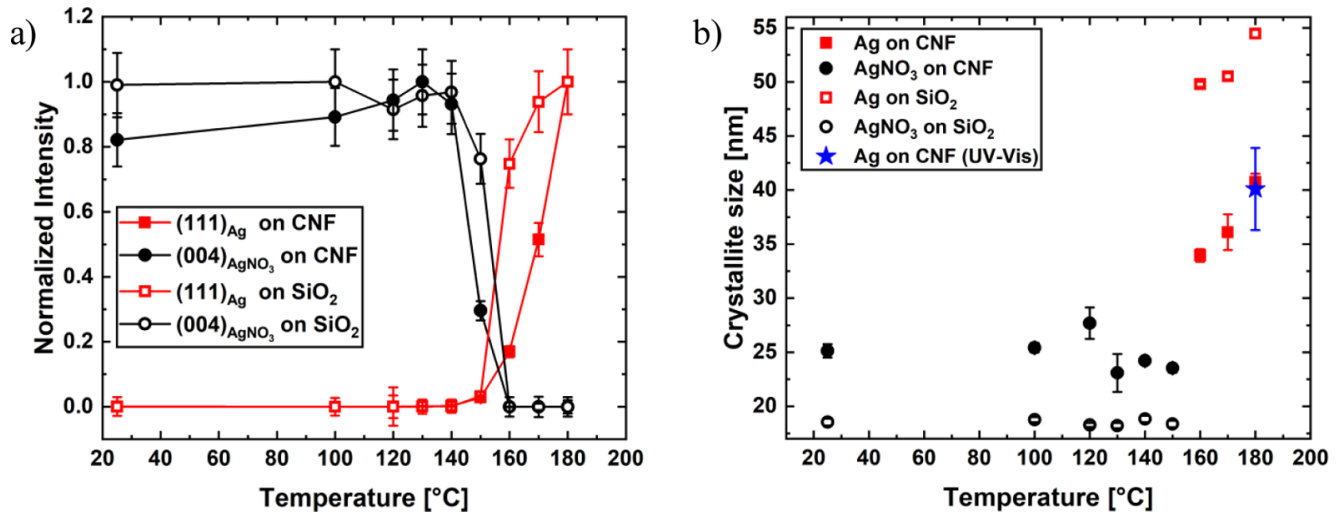

Figure 3. (a) Normalized intensity of WAXS peaks during $\mathrm{AgNO}_{3}$ decomposition for the $\mathrm{SiO}_{2}$ [open symbols] and CNF substrates [closed symbols]. The intensity of the $\mathrm{AgNO}_{3}(004)$ [black] and $\mathrm{Ag}(111)$ [red] peaks is shown with increasing temperature up to $180{ }^{\circ} \mathrm{C}$. (b) Crystallite sizes calculated using the Scherrer equation and retrieved for $\mathrm{AgNO}_{3}$ and metallic Ag nanoparticles. The particle size of the UV-vis [blue] matches with the particle size deduced by WAXS.

a)

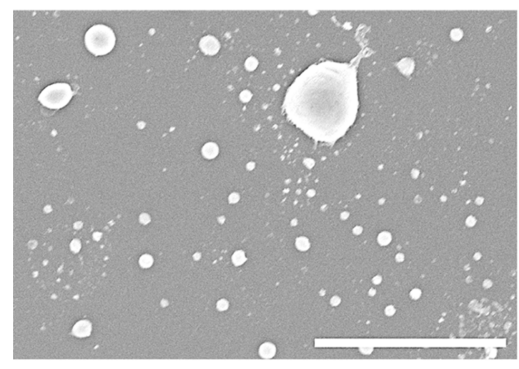

c)

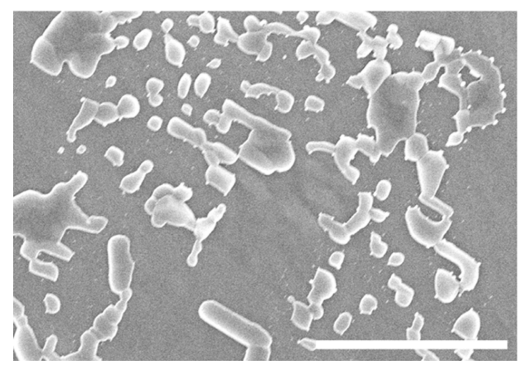

b)

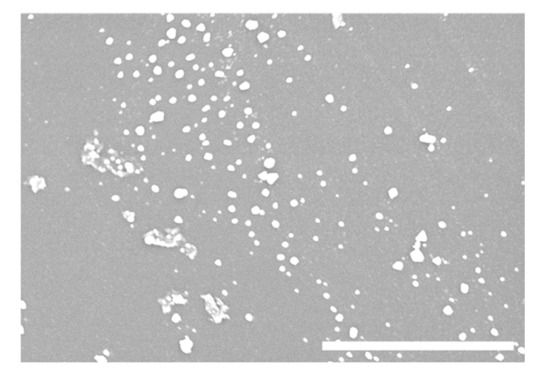

d)

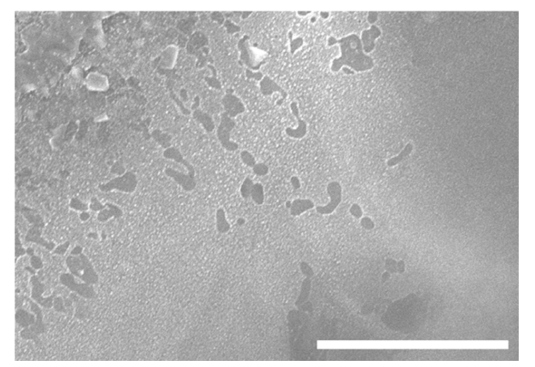

Figure 4. SEM images of the spray-deposited $\mathrm{AgNO}_{3}$ precursor on $(\mathrm{a}, \mathrm{b}) \mathrm{SiO}_{2}$ and $(\mathrm{c}, \mathrm{d}) \mathrm{CNF}$ thin films; (a,c) before and (b,d) after annealing to $180^{\circ} \mathrm{C}$. The scale bar equals $4 \mu \mathrm{m}$.

on a CNF substrate, but with a significantly higher intensity and a lower full-width at half-maximum (fwhm) of the plasmonic peak at $(419 \pm 1) \mathrm{nm}$. The smaller-sized Ag nanoparticles on CNFs are an improvement over the large $\mathrm{Ag}$ nanoparticles with lower density on $\mathrm{SiO}_{2}$. The region around $341 \mathrm{~nm}$ is visible during the first $30 \mathrm{~s}$ and follows the same trend. The $\mathrm{AgNO}_{3}$ peak disappears, at the same time the $\mathrm{Ag}$ plasmonic absorption peak appears, see Figure $1 \mathrm{~b}$ ).

The low intensity of the silver plasmonic signal on $\mathrm{SiO}_{2}$ substrates allowed for an extended analysis only for the case of Ag nanoparticles on a CNF substrate. The deposited amount of $\mathrm{AgNO}_{3}$ was equal on both substrates and hence one can conclude already a lower coverage of the Ag nanoparticles after reduction on $\mathrm{SiO}_{2}$. The UV-vis spectroscopy data are evaluated using a Mie-Gans fitting approach as introduced by Amendola and Meneghetti for gold nanoparticles in solution. ${ }^{37}$ For the evaluation, the Fermi velocity $\nu_{\mathrm{F}}=1.39$ $\times 10^{6} \mathrm{~m} / \mathrm{s}$ and the dielectric function of $\mathrm{Ag}$ are fed in the
Mathematica program LNMG, where the spectra are fitted, see (Figure $2 \mathrm{~b}) .{ }^{37,38}$ This gives a nanoparticle size of $(40.1 \pm 3.8)$ $\mathrm{nm}$ with a Log-normal distribution consisting of $98 \%$ spherical particles and $2 \%$ spheroidal particles, see Figure S1. Liu et al. showed for gold nanoparticles that the electronic band gap is present when the particles are very small, i.e., below $3 \mathrm{~nm}$.

From the UV-vis spectra, we further evaluated the Tauc plot in Figure 2c, where we fit a straight line to the linear part of the peak, see the inset in Figure 2c, to extract the energy band gap of the synthesized $\mathrm{Ag}$ nanoparticles, see Figure $2 \mathrm{~d} .{ }^{40}$ It increases from around $E_{\mathrm{g}}=2.3 \mathrm{eV}$ to $E_{\mathrm{g}}=2.58 \mathrm{eV}$ and after $125 \mathrm{~s}$, it remains constant. This feature presents an opportunity for tuning of the energy band gap for optoelectronic applications on a bio-based renewable cellulose substrate. The constant band gap is the metallic silver band gap, meaning that the surrounding medium has not influenced the band gap. 
a)

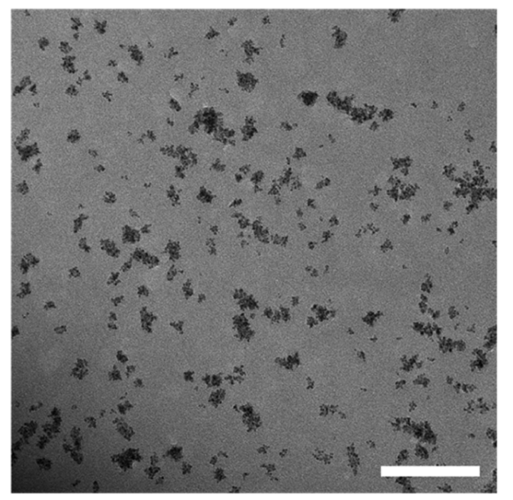

c)

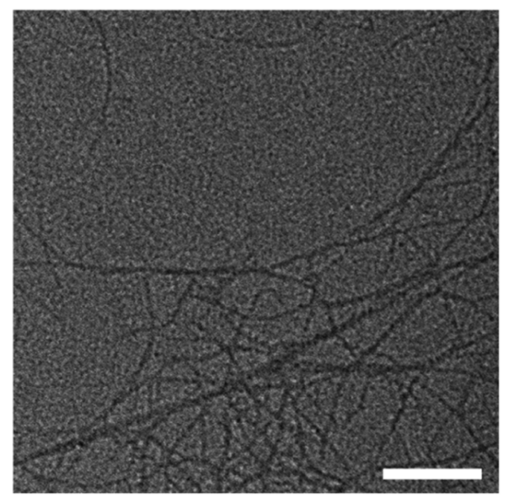

e)

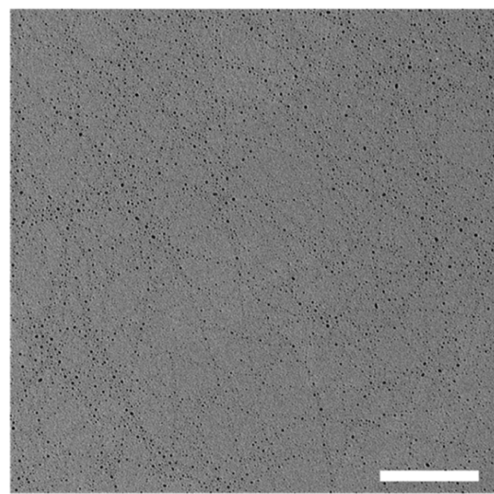

b)

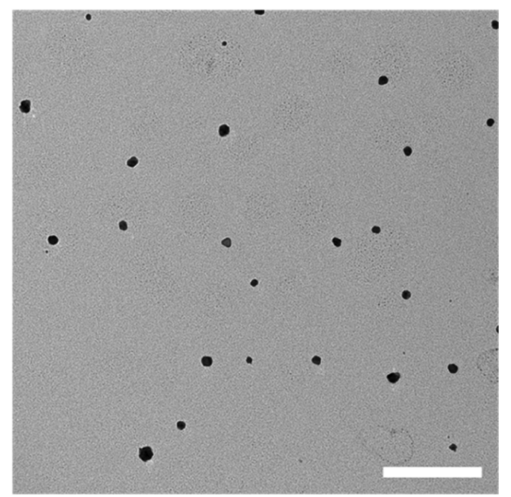

d)

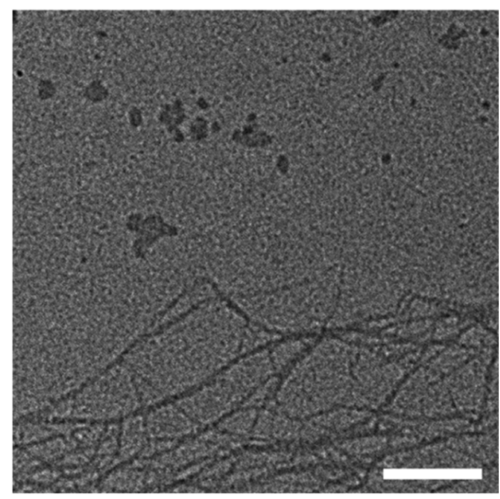

f)

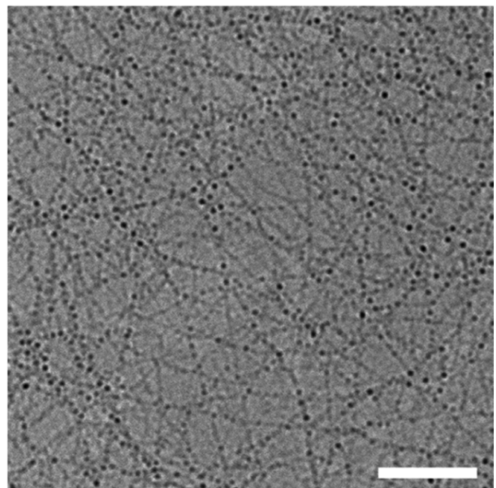

Figure 5. TEM images of the different states of $\mathrm{AgNO}_{3}$ and $\mathrm{Ag}$ on glass and CNF substrates. (a) $\mathrm{AgNO}_{3}$ on glass, (b) $\mathrm{Ag}$ on glass, (c) CNFs on glass, (d) $\mathrm{AgNO}_{3}$ on CNFs, (e) $\mathrm{Ag}$ on CNFs, and (f) $\mathrm{Ag}$ on CNFs. Samples (e,f) show the same area with a different focus to visualize the decoration of the CNFs with $\mathrm{Ag}$ nanoparticles. The scale bar is $200 \mathrm{~nm}$.

3.2. Crystal Size Growth. WAXS measurements are performed in transmission on the two different substrates. The samples are measured at different temperatures ranging from room temperature up to $180{ }^{\circ} \mathrm{C}$, and the detected $\mathrm{AgNO}_{3}$ and $\mathrm{Ag} \mathrm{Bragg}$ peaks are fitted, see Figure S2. In Figure 3, the normalized intensities of the $\mathrm{AgNO}_{3}(004)$ and $\mathrm{Ag}(111)$ Bragg peaks are plotted versus the temperature. The peak intensity changes show that $\mathrm{AgNO}_{3}$ disappears entirely between 150 and $160{ }^{\circ} \mathrm{C}$, by transforming into metallic Ag. Carbonization of the CNF template could not be resolved during the thermal annealing. From the Scherrer equation and the fitted fwhm of the peaks, the crystallite sizes are estimated, see Figure $3 \mathrm{~b}$. The crystallite size is approximately constant up to $150{ }^{\circ} \mathrm{C}$ at $(18.5 \pm 0.3) \mathrm{nm}$ and $(24.8 \pm 0.8) \mathrm{nm}$ for $\mathrm{AgNO}_{3}$ crystallites on $\mathrm{SiO}_{2}$ and CNF substrate, respectively. After transformation to metallic $\mathrm{Ag}$, the nanoparticles grow from $(49.7 \pm 0.2)$ to $(54.4 \pm 0.4) \mathrm{nm}$ on $\mathrm{SiO}_{2}$ and from $(33.9 \pm$ $0.5)$ to $(40.7 \pm 0.7) \mathrm{nm}$ on the CNF substrate. The nanoparticle size estimated from the WAXS data agrees well with the UV-vis result of $(40.1 \pm 3.8) \mathrm{nm}$, although with a narrower distribution.

3.3. Large-Scale Arrangement. SEM measurements are performed on the same samples to gain a real-space image of the spray-deposited $\mathrm{AgNO}_{3}$ on the $\mathrm{SiO}_{2}$ and the thin CNF 
templates before and after thermal annealing, see Figure 4. The spray-deposited $\mathrm{AgNO}_{3}$ on $\mathrm{SiO}_{2}$ in Figure 4a forms visible spherical particles in the few hundreds of nanometer range. On the CNF film seen in Figure 4c, the deposited $\mathrm{AgNO}_{3}$ forms more elongated interconnected structures with a wider lateral spread compared to the $\mathrm{SiO}_{2}$ substrate, showing a better surface wetting. The shape of the $\mathrm{AgNO}_{3}$ on top of the CNFs can be related to the initial rectangular form of the CNF. ${ }^{41}$ In Figure $4 \mathrm{~b}$, the thermally annealed $\mathrm{AgNO}_{3}$ on $\mathrm{SiO}_{2}$ can be seen. One clearly sees that the former macroscopic microscale $\mathrm{AgNO}_{3}$ particles decrease in size additionally to the increase mentioned above in the WAXS-retrieved nanoscale nanoparticle size. This is important as the physical properties are governed on the nanoscale. The annealed $\mathrm{AgNO}_{3}$ on the cellulose substrate forms a film on top of the cellulose with a granular nanostructure, see Figure 4d.

TEM measurements are performed on TEM grids with a single spray pulse of either $\mathrm{AgNO}_{3}, \mathrm{Ag}$ after thermal decomposition or on a single spray pulse of CNFs. In Figure $5 \mathrm{a}, \mathrm{b}$, the decomposition of $\mathrm{AgNO}_{3}$ to $\mathrm{Ag}$ on the $\mathrm{SiO}_{2}$ substrate is shown. It is clearly visible that fully separated spheroidal nanoparticles are fabricated. In Figure 5c, the CNF is shown from a single spray pulse, which explains the not fully percolated network. In Figure $5 \mathrm{~d}$, the $\mathrm{CNF}$ as well as the $\mathrm{AgNO}_{3}$ is shown; however, the $\mathrm{AgNO}_{3}$ is not visible on the $\mathrm{CNF}$ due to lack of contrast. Figure 5e,f shows the CNF network with the $\mathrm{Ag}$ nanoparticles after thermal decomposition. Here, the TEM images show the same area with different foci. The nanoparticles seem to decorate the CNF along its fibrous structure and do not appear on the empty spaces in-between the CNF network. The TEM measurements show the guided $\mathrm{Ag}$ growth on the CNF agglomerates. We believe that the surface charge induces the localized reduction of the $\mathrm{AgNO}_{3}$ and bonding of the growing $\mathrm{Ag}$ nanoparticles on these sites. The CNF structure remains intact after thermal annealing to $180{ }^{\circ} \mathrm{C}$, which is well below the thermal degradation temperature of around $220{ }^{\circ} \mathrm{C}$ of the TEMPO$\mathrm{CNF}^{42}$ Previously, the CNF with different surface charges were studied concerning their wettability and morphology. ${ }^{7,43}$ We would expect that a lower surface charge would lead to a lower coverage of the CNF agglomerates.

3.4. Nanoscale Self-Assembly. Large-area evaluation of the nanoscale structure of these spray-deposited films is performed with GISAXS, where he samples are prepared as for the UV-vis and WAXS characterization. These samples are annealed $e x$ situ and measured directly after thermal treatment. In Figure S3, the scattering patterns of the substrate $+\mathrm{AgNO}_{3}$ and substrate $+\mathrm{Ag}$ are shown for both substrates. In Figure 6, the horizontal line cuts of the 2D GISAXS data as a function of $q_{y}$ are shown. The cuts are performed in the Yoneda region of $\mathrm{AgNO}_{3}$ and $\mathrm{Ag}$, respectively.

From the scattering patterns as well as from the onedimensional integrations, one can clearly see the difference for the different substrates. Although the difference is small when depositing $\mathrm{AgNO}_{3}$, the transformation to $\mathrm{Ag}$ results in significant differences depending on the substrate. Regarding $\mathrm{AgNO}_{3}$, structures on the CNF thin film are smaller when compared to the reference $\mathrm{SiO}_{2}$ substrate, similar to what is found for macroscopic length scales as seen in Figure 4,5. GISAXS gives a surface-averaged estimate of the mean dimensions of the nanoparticles as well as the structure of their two-dimensional distribution on the surface. After thermal annealing of the $\mathrm{AgNO}_{3}$ samples and the full

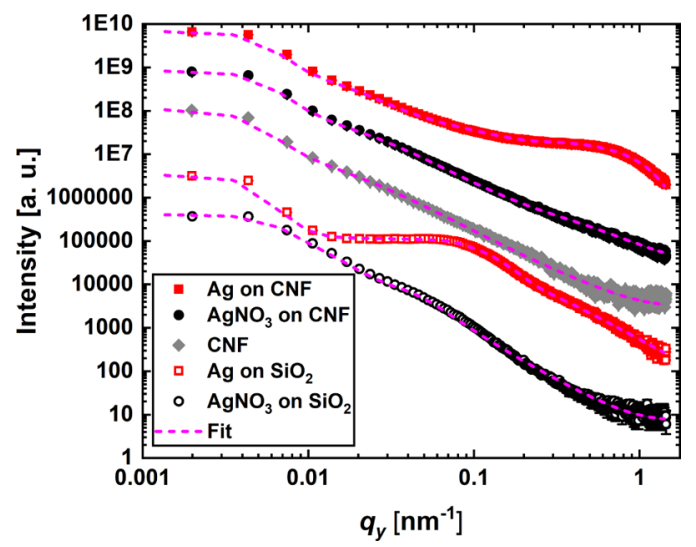

Figure 6. Horizontal line cuts of the 2D GISAXS data (symbols) shown together with fits (dashed lines). The $\mathrm{AgNO}_{3}$ samples are shown in black, Ag samples with red symbols, and the CNF with gray symbols. The closed and open symbols represent the sample on CNFs and $\mathrm{SiO}_{2}$, respectively. The data are shifted vertically for visualization.

transformation to metallic Ag, we observe an intensity maxima at $q_{y} \approx 0.1 \mathrm{~nm}^{-1}$ and $q_{y} \approx 0.8 \mathrm{~nm}^{-1}$ for the $\mathrm{SiO}_{2}$ and $\mathrm{CNF}$ substrate, respectively. This implies that we fabricate nanoparticles for both cases, but with distinct size differences: larger nanoparticles on $\mathrm{SiO}_{2}$ and smaller ones on CNFs. All fit parameters are reported in Table S1. The CNF substrate structures are similar to the previously published result, where we observe a bimodal cylindrical form factor in a paracrystalline plane. ${ }^{7}$ This model is used and is not changed further to describe the $\mathrm{CNF}$ substrate. The deposited $\mathrm{AgNO}_{3}$ and the $\mathrm{Ag}$ nanoparticles residing on top of the CNF template or the bare $\mathrm{SiO}_{2}$ substrate are modeled with either a single or double modal spherical form factor in a paracrystalline plane. On the $\mathrm{CNF}$ template, $\mathrm{AgNO}_{3}$ decomposes to $\mathrm{Ag}$ which causes the nanoparticle radius to change from $r_{\mathrm{AgNO} 3}=(7.2 \pm 0.4) \mathrm{nm}$ to $r_{\mathrm{Ag}}=(1.9 \pm 0.4) \mathrm{nm}$ with a center-to-center distance of the nanoparticles increasing from $d_{\mathrm{AgNO} 3}=(40.6 \pm 5.6) \mathrm{nm}$ to $d_{\mathrm{Ag}}$ $=(60.2 \pm 29.8) \mathrm{nm}$. Large Ag nanoparticles as extracted from $\mathrm{UV}-$ vis and WAXS measurements are not found on the CNF as the size of these particles incidentally overlaps with the initial size of the CNFs. On $\mathrm{SiO}_{2}, \mathrm{AgNO}_{3}$ decomposition results in turning a single-form factor nanostructure into a double-form factor nanostructure. $\mathrm{AgNO}_{3}$ nanoparticles have a radius of $r_{\mathrm{AgNO} 3}=(37.2 \pm 11.5) \mathrm{nm}$ and a center-to-center distance of $d_{\mathrm{AgNO} 3}=(95.7 \pm 52.2) \mathrm{nm}$. The large $\mathrm{Ag}$ nanoparticles on $\mathrm{SiO}_{2}$ have a radius of $r_{1, \mathrm{Ag}}=(27.7 \pm 7.7) \mathrm{nm}$ with a center-to-center distance of $d_{1, \mathrm{Ag}}=(255 \pm 74) \mathrm{nm}$ and the small ones have a radius of $r_{2, \mathrm{Ag}}=(1.7 \pm 0.8) \mathrm{nm}$ with a center-to-center distance of $d_{1, \mathrm{Ag}}=(133 \pm 32) \mathrm{nm}$. We extract from the fitted sizes in GISAXS the surface coverage by calculating the percentage coverage from the individual particles on a square with the size of the center-to-center distance. For $\mathrm{AgNO}_{3}$ on the $\mathrm{CNF}$, we have a coverage of $\approx 9.8 \%$, while $\mathrm{Ag}$ on the $\mathrm{CNF}$ has a coverage of $\approx 0.03 \%$. $\mathrm{AgNO}_{3}$ on $\mathrm{SiO}_{2}$ covers about $\approx 47.5 \%$ and $\mathrm{Ag}$ on $\mathrm{SiO}_{2}$ has a coverage of $\approx 3.7 \%$ for the large cluster and $\approx 0.05 \%$ for the small cluster. It must be noted that GISAXS resolves the nanoscale objects and larger agglomerates, as seen in SEM, are moved into the resolution limit to enhance the sensitivity toward nanoscale structures, which are difficult to be resolved with SEM. TEM, on the other hand, resolved the nanoparticles to be well distributed and match in sizes with those extracted by GISAXS. Therefore, GISAXS, SEM, and TEM have a 
certain complementarity. On both substrates, the smaller particles can be found; however, on the bare $\mathrm{SiO}_{2}$ substrate, larger structures evolve, which may be attributed to coalescence being inhibited on the porous CNF substrate. Although the same amount of $\mathrm{AgNO}_{3}$ is deposited on both substrates, only the CNF substrate exhibits a plasmonic behavior. The loss of a plasmonic signal in the case of the $\mathrm{SiO}_{2}$ substrate is attributed to the formation of too large nanostructures on the expense of the plasmon-active small nanostructures, which therefore remain in a too low concentration. The CNF-mediated growth leads to smaller nanoparticles that are also more homogeneously distributed on the surface, enabling a distinct plasmonic behavior.

\section{CONCLUSIONS}

We present a facile fabrication of biocompatible thin films with tunable optical responses. By combining spectroscopic methods with X-ray scattering techniques, we are able to elucidate the changes in the nanoparticle dimensions and surface structure distribution before, during, and after the thermal transition of an $\mathrm{AgNO}_{3}$ precursor to metallic Ag. The biocompatible substrate is a nanocellulose film, which is compared to a non-porous hard $\mathrm{SiO}_{2}$ reference substrate. The CNF template-assisted growth allows us to study, with minimal material usage, the tunability of the electronic band gap by looking into different timescales of the thermal transformation. The soft and nanoporous cellulosic thin films provide a promising route for further evaluation with respect to their use to tune the electronic band gap in applications such as flexible nanoparticle bulk heterojunction solar cells.

\section{ASSOCIATED CONTENT}

\section{SI Supporting Information}

The Supporting Information is available free of charge at https://pubs.acs.org/doi/10.1021/acsami.1c07544.

UV--vis fitting, WAXS data, GISAXS pattern, and GISAXS fit results (PDF)

\section{AUTHOR INFORMATION}

\section{Corresponding Authors}

Calvin J. Brett - Department of Engineering Mechanics, KTH Royal Institute of Technology, 10044 Stockholm, Sweden; Wallenberg Wood Science Center, KTH Royal Institute of Technology, 10044 Stockholm, Sweden; Deutsches Elektronen-Synchrotron DESY, Ein Forschungszentrum der Helmholtz-Gemeinschaft, 22607 Hamburg, Germany; ○ orcid.org/0000-0001-5789-6299; Email: calvinbr@ kth.se

L. Daniel Söderberg - Department of Engineering Mechanics, KTH Royal Institute of Technology, 10044 Stockholm, Sweden; Wallenberg Wood Science Center, KTH Royal Institute of Technology, 10044 Stockholm, Sweden; (1) orcid.org/0000-0003-3737-0091; Email: dansod@kth.se

Stephan V. Roth - Deutsches Elektronen-Synchrotron DESY, Ein Forschungszentrum der Helmholtz-Gemeinschaft, 22607 Hamburg, Germany; Department of Fibre and Polymer Technology, Division of Coating Technology, 10044 Stockholm, Sweden; (1) orcid.org/0000-0002-6940-6012; Email: stephan.roth@desy.de

\section{Authors}

Wiebke Ohm - Deutsches Elektronen-Synchrotron DESY, Ein Forschungszentrum der Helmholtz-Gemeinschaft, 22607 Hamburg, Germany

Björn Fricke - Deutsches Elektronen-Synchrotron DESY, Ein Forschungszentrum der Helmholtz-Gemeinschaft, 22607 Hamburg, Germany

Alexandros E. Alexakis - Wallenberg Wood Science Center, KTH Royal Institute of Technology, 10044 Stockholm, Sweden; Department of Fibre and Polymer Technology, Division of Coating Technology, 10044 Stockholm, Sweden

Tim Laarmann - Deutsches Elektronen-Synchrotron DESY, Ein Forschungszentrum der Helmholtz-Gemeinschaft, 22607 Hamburg, Germany; The Hamburg Centre for Ultrafast Imaging CUI, 22761 Hamburg, Germany

Volker Körstgens - Lehrstuhl für Funktionelle Materialien, Physik-Department, Technische Universität München, 85748 Garching, Germany; (1) orcid.org/0000-0001-7178-5130

Peter Müller-Buschbaum - Lehrstuhl für Funktionelle Materialien, Physik-Department, Technische Universität München, 85748 Garching, Germany; Heinz Maier-Leibnitz Zentrum (MLZ), Technische Universität München, 85748 Garching, Germany; 이이이.org/0000-0002-9566-6088

Complete contact information is available at: https://pubs.acs.org/10.1021/acsami.1c07544

\section{Notes}

The authors declare no competing financial interest.

\section{ACKNOWLEDGMENTS}

We thank Dr. Nitesh Mittal for providing the nanocellulose. We thank Prof. Eva Malmström for supporting with TEM measurements. We acknowledge DESY (Hamburg, Germany), a member of the Helmholtz Association HGF, for the provision of experimental facilities. Parts of this research were carried out at PETRA III beamline P03. C.J.B. and S.V.R. acknowledge financial support from DESY strategic fund (DSF) "Investigation of processes for spraying and spraycoating of hybrid cellulose-based nanostructures". We thank financial support by the Knut and Alice Wallenberg Foundation through Wallenberg Wood Science Center at $\mathrm{KTH}$. PMB and VK acknowledge funding from Deutsche Forschungsgemeinschaft (DFG, German Research Foundation) via International Research Training Group 2022 Alberta/ Technical University of Munich International Graduate School for Environmentally Responsible Functional Materials (ATUMS) and under Germanýs Excellence Strategy-EXC 2089/1-390776260 (e-conversion).

\section{REFERENCES}

(1) Chen, C.; Kuang, Y.; Zhu, S.; Burgert, I.; Keplinger, T.; Gong, A.; Li, T.; Berglund, L.; Eichhorn, S. J.; Hu, L. Structure-propertyfunction relationships of natural and engineered wood. Nat. Rev. Mater. 2020, 5, 642-666.

(2) Mittal, N.; Ansari, F.; Gowda, V. K.; Brouzet, C.; Chen, P.; Larsson, P. T.; Roth, S. V.; Lundell, F.; Wågberg, L.; Kotov, N. A.; Söderberg, L. D. Multiscale Control of Nanocellulose Assembly: Transferring Remarkable Nanoscale Fibril Mechanics to Macroscale Fibers. ACS Nano 2018, 12, 6378-6388.

(3) Say, M. G.; Brooke, R.; Edberg, J.; Grimoldi, A.; Belaineh, D.; Engquist, I.; Berggren, M. Spray-Coated Paper Supercapacitors. npj Flexible Electron. 2020, 4, 14.

(4) Wang, R.; Yu, H.; Dirican, M.; Chen, L.; Fang, D.; Tian, Y.; Yan, C.; Xie, J.; Jia, D.; Liu, H.; Wang, J.; Tang, F.; Asiri, A. M.; Zhang, X.; 
Tao, J. Highly Transparent, Thermally Stable, and Mechanically Robust Hybrid Cellulose-Nanofiber/Polymer Substrates for the Electrodes of Flexible Solar Cells. ACS Appl. Energy Mater. 2020, 3, 785-793.

(5) Wu, J.; Che, X.; Hu, H.-C.; Xu, H.; Li, B.; Liu, Y.; Li, J.; Ni, Y.; Zhang, X.; Ouyang, X. Organic Solar Cells Based on Cellulose Nanopaper from Agroforestry Residues with an Efficiency of over $16 \%$ and Effectively Wide-Angle Light Capturing. J. Mater. Chem. A 2020, 8, 5442-5448.

(6) Li, H.; Kruteva, M.; Mystek, K.; Dulle, M.; Ji, W.; Pettersson, T.; Wagberg, L. Macro- and Microstructural Evolution during Drying of Regenerated Cellulose Beads. ACS Nano 2020, 14, 6774-6784.

(7) Brett, C. J.; Mittal, N.; Ohm, W.; Gensch, M.; Kreuzer, L. P.; Körstgens, V.; Månsson, M.; Frielinghaus, H.; Müller-Buschbaum, P.; Söderberg, L. D.; Roth, S. V. Water-Induced Structural Rearrangements on the Nanoscale in Ultrathin Nanocellulose Films. Macromolecules 2019, 52, 4721-4728.

(8) Sun, C.; Zhu, D.; Jia, H.; Lei, K.; Zheng, Z.; Wang, X. Humidity and Heat Dual Response Cellulose Nanocrystals/Poly(N-Isopropylacrylamide) Composite Films with Cyclic Performance. ACS Appl. Mater. Interfaces 2019, 11, 39192.

(9) Zhu, Q.; Liu, S.; Sun, J.; Liu, J.; Kirubaharan, C. J.; Chen, H.; Xu, W.; Wang, Q. Stimuli-Responsive Cellulose Nanomaterials for Smart Applications. Carbohydr. Polym. 2020, 235, 115933.

(10) Garemark, J.; Yang, X.; Sheng, X.; Cheung, O.; Sun, L.; Berglund, L. A.; Li, Y. Top-Down Approach Making Anisotropic Cellulose Aerogels as Universal Substrates for Multifunctionalization. ACS Nano 2020, 14, 7111-7120.

(11) Gordeyeva, K. S.; Fall, A. B.; Hall, S.; Wicklein, B.; Bergström, L. Stabilizing Nanocellulose-Nonionic Surfactant Composite Foams by Delayed Ca-Induced Gelation. J. Colloid Interface Sci. 2016, 472, 44-51.

(12) Nordenström, M.; Fall, A.; Nyström, G.; Wågberg, L. Formation of Colloidal Nanocellulose Glasses and Gels. Langmuir 2017, 33, 9772-9780.

(13) Jones, A. O. F.; Resel, R.; Schrode, B.; Machado-Charry, E.; Röthel, C.; Kunert, B.; Salzmann, I.; Kontturi, E.; Reishofer, D.; Spirk, S. Structural Order in Cellulose Thin Films Prepared from a Trimethylsilyl Precursor. Biomacromolecules 2020, 21, 653-659.

(14) Hu, D.; Ma, W.; Zhang, Z.; Ding, Y.; Wu, L. Dual Bio-Inspired Design of Highly Thermally Conductive and Superhydrophobic Nanocellulose Composite Films. ACS Appl. Mater. Interfaces 2020, 12, 11115-11125.

(15) Françon, H.; Wang, Z.; Marais, A.; Mystek, K.; Piper, A.; Granberg, H.; Malti, A.; Gatenholm, P.; Larsson, P. A.; Wågberg, L. Ambient-Dried, 3D-Printable and Electrically Conducting Cellulose Nanofiber Aerogels by Inclusion of Functional Polymers. Adv. Funct. Mater. 2020, 30, 1909383.

(16) Santoro, G.; Yu, S.; Schwartzkopf, M.; Zhang, P.; Koyiloth Vayalil, S.; Risch, J. F. H.; Rübhausen, M. A.; Hernández, M.; Domingo, C.; Roth, S. V. Silver Substrates for Surface Enhanced Raman Scattering: Correlation between Nanostructure and Raman Scattering Enhancement. Appl. Phys. Lett. 2014, 104, 243107.

(17) Abd El-Fattah, Z. M.; Mkhitaryan, V.; Brede, J.; Fernández, L.; Li, C.; Guo, Q.; Ghosh, A.; Echarri, A. R.; Naveh, D.; Xia, F.; Ortega, J. E.; García de Abajo, F. J. Plasmonics in Atomically Thin Crystalline Silver Films. ACS Nano 2019, 13, 7771-7779.

(18) Hu, H.; Pauly, M.; Felix, O.; Decher, G. Spray-Assisted Alignment of Layer-by-Layer Assembled Silver Nanowires: A General Approach for the Preparation of Highly Anisotropic Nano-Composite Films. Nanoscale 2017, 9, 1307-1314.

(19) Glier, T. E.; Akinsinde, L.; Paufler, M.; Otto, F.; Hashemi, M.; Grote, L.; Daams, L.; Neuber, G.; Grimm-Lebsanft, B.; Biebl, F.; Rukser, D.; Lippmann, M.; Ohm, W.; Schwartzkopf, M.; Brett, C. J.; Matsuyama, T.; Roth, S. V.; Rübhausen, M. Functional Printing of Conductive Silver-Nanowire Photopolymer Composites. Sci. Rep. 2019, 9, 6465.

(20) Dumée, L. F.; Yi, Z.; Tardy, B.; Merenda, A.; des Ligneris, E.; Dagastine, R. R.; Kong, L. Silver Metal Nano-Matrixes as High
Efficiency and Versatile Catalytic Reactors for Environmental Remediation. Sci. Rep. 2017, 7, 45112.

(21) Byrne, D.; Zhao, Y.; O’Brien, P.; McDonagh, C. Direct Spray Deposition of Silver Nanoparticle Films for Biosensing Applications. RSC Adv. 2015, 5, 62836-62843.

(22) Vivekanandhan, S.; Christensen, L.; Misra, M.; Kumar Mohanty, A. Green Process for Impregnation of Silver Nanoparticles into Microcrystalline Cellulose and Their Antimicrobial Bionanocomposite Films. J. Biomater. Nanobiotechnol. 2012, 03, 371-376.

(23) Phan, D.-N.; Dorjjugder, N.; Khan, M. Q.; Saito, Y.; Taguchi, G.; Lee, H.; Mukai, Y.; Kim, I.-S. Synthesis and Attachment of Silver and Copper Nanoparticles on Cellulose Nanofibers and Comparative Antibacterial Study. Cellulose 2019, 26, 6629-6640.

(24) Ifuku, S.; Tsuji, M.; Morimoto, M.; Saimoto, H.; Yano, H. Synthesis of Silver Nanoparticles Templated by TEMPO-Mediated Oxidized Bacterial Cellulose Nanofibers. Biomacromolecules 2009, 10, 2714-2717.

(25) Hsieh, M.-C.; Kim, C.; Nogi, M.; Suganuma, K. Electrically Conductive Lines on Cellulose Nanopaper for Flexible Electrical Devices. Nanoscale 2013, 5, 9289.

(26) Nogi, M.; Karakawa, M.; Komoda, N.; Yagyu, H.; Nge, T. T. Transparent Conductive Nanofiber Paper for Foldable Solar Cells. Sci. Rep. 2015, 5, 17254.

(27) Al-Hussein, M.; Herzig, E. M.; Schindler, M.; Löhrer, F.; Palumbiny, C. M.; Wang, W.; Roth, S. V.; Müller-Buschbaum, P. Comparative Study of the Nanomorphology of Spray and Spin Coated PTB7 Polymer: Fullerene Films. Polym. Eng. Sci. 2016, 56, 889-894.

(28) Richardson, J. J.; Bjornmalm, M.; Caruso, F. TechnologyDriven Layer-by-Layer Assembly of Nanofilms. Science 2015, 348, aa2491.

(29) Park, J. H.; Ambwani, P.; Manno, M.; Lindquist, N. C.; Nagpal, P.; Oh, S.-H.; Leighton, C.; Norris, D. J. Single-Crystalline Silver Films for Plasmonics. Adv. Mater. 2012, 24, 3988-3992.

(30) Engström, J.; Brett, C. J.; Körstgens, V.; Müller-Buschbaum, P.; Ohm, W.; Malmström, E.; Roth, S. V. Core-Shell Nanoparticle Interface and Wetting Properties. Adv. Funct. Mater. 2020, 30, 1907720.

(31) Ohm, W.; Rothkirch, A.; Pandit, P.; Körstgens, V.; MüllerBuschbaum, P.; Rojas, R.; Yu, S.; Brett, C. J.; Söderberg, D. L.; Roth, S. V. Morphological Properties of Airbrush Spray-Deposited Enzymatic Cellulose Thin Films. J. Coating Technol. Res. 2018, 15, 759-769.

(32) Jawerth, M. E.; Brett, C. J.; Terrier, C.; Larsson, P. T.; Lawoko, M.; Roth, S. V.; Lundmark, S.; Johansson, M. Mechanical and Morphological Properties of Lignin-Based Thermosets. ACS Appl. Polym. Mater. 2020, 2, 668-676.

(33) Isogai, A.; Saito, T.; Fukuzumi, H. TEMPO-Oxidized Cellulose Nanofibers. Nanoscale 2011, 3, 71-85.

(34) Dosch, H.; Batterman, B. W.; Wack, D. C. Depth-Controlled Grazing-Incidence Diffraction of Synchrotron X Radiation. Phys. Rev. Lett. 1986, 56, 1144-1147.

(35) Benecke, G.; Wagermaier, W.; Li, C.; Schwartzkopf, M.; Flucke, G.; Hoerth, R.; Zizak, I.; Burghammer, M.; Metwalli, E.; MüllerBuschbaum, P.; Trebbin, M.; Förster, S.; Paris, O.; Roth, S. V.; Fratzl, P. A customizable software for fast reduction and analysis of large $\mathrm{X}$ ray scattering data sets: applications of the newDPDAKpackage to small-angle X-ray scattering and grazing-incidence small-angle X-ray scattering. J. Appl. Crystallogr. 2014, 47, 1797-1803.

(36) Li, Z.; Wang, L.; Chen, S.; Feng, C.; Chen, S.; Yin, N.; Yang, J.; Wang, H.; Xu, Y. Facilely Green Synthesis of Silver Nanoparticles into Bacterial Cellulose. Cellulose 2015, 22, 373-383.

(37) Amendola, V.; Meneghetti, M. Size Evaluation of Gold Nanoparticles by UV-vis Spectroscopy. J. Phys. Chem. C 2009, 113, $4277-4285$.

(38) Yang, H. U.; D’Archangel, J.; Sundheimer, M. L.; Tucker, E.; Boreman, G. D.; Raschke, M. B. Optical Dielectric Function of Silver. Phys. Rev. B: Condens. Matter Mater. Phys. 2015, 91, 235137. 
(39) Liu, H.; Mun, B. S.; Thornton, G.; Isaacs, S. R.; Shon, Y.-S.; Ogletree, D. F.; Salmeron, M. Electronic Structure of Ensembles of Gold Nanoparticles: Size and Proximity Effects. Phys. Rev. B: Condens. Matter Mater. Phys. 2005, 72, 155430.

(40) Tauc, J. Optical Properties and Electronic Structure of Amorphous Ge and Si. Mater. Res. Bull. 1968, 3, 37-46.

(41) López Durán, V.; Hellwig, J.; Larsson, P. T.; Wågberg, L.; Larsson, P. A. Effect of Chemical Functionality on the Mechanical and Barrier Performance of Nanocellulose Films. ACS Appl. Nano Mater. 2018, 1, 1959-1967.

(42) Lichtenstein, K.; Lavoine, N. Toward a Deeper Understanding of the Thermal Degradation Mechanism of Nanocellulose. Polym. Degrad. Stab. 2017, 146, 53-60.

(43) Chen, Q.; Brett, C. J.; Chumakov, A.; Gensch, M.; Schwartzkopf, M.; Körstgens, V.; Söderberg, L. D.; Plech, A.; Zhang, P.; Müller-Buschbaum, P.; Roth, S. V. Layer-by-Layer SprayCoating of Cellulose Nanofibrils and Silver Nanoparticles for Hydrophilic Interfaces. ACS Appl. Nano Mater. 2021, 4, 503-513. 